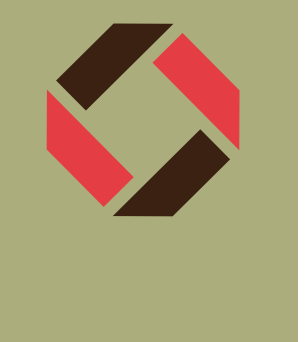

\title{
Minerals with a mission
}

\section{Carol Jantzen establishes Fredericks Mineral Gallery for STEM education}

\author{
rpsec.usca.edu/FredericksMineralGallery
}

\section{By Gail A. Oare}

\begin{abstract}
250-pound single crystal of feldspar A that is at least 350 million years old ... Crab, bird track and crinoid fossils, fulgurites, tomahawk heads and arrowheads made of obsidian ... A 95-million-year-old raptor egg found in Mongolia - one of only six in the United States.

These are just a few of the extraordinary pieces from the more than 1000 rocks and minerals that Carol Jantzen is donating to establish the Fredericks Mineral Gallery. It is located at the Ruth Patrick Science Education Center (RPSEC) in Aiken, S.C. The gallery is named in honor of Jantzen's parents, the late Theodore (Ted) and Clara Fredericks, and consists of the massive collection acquired over decades by Jantzen and her father.
\end{abstract}

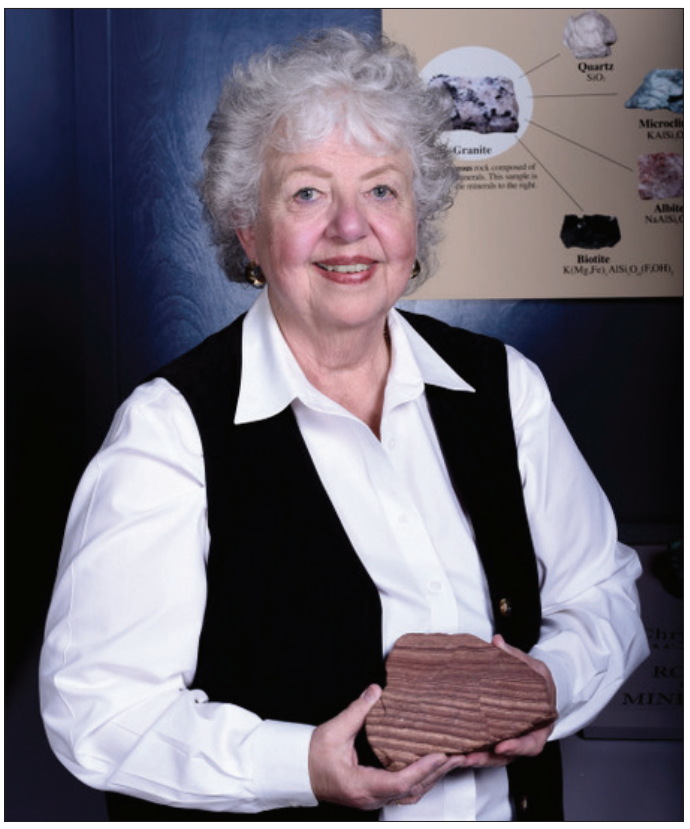

Carol Jantzen in the Fredericks Mineral Gallery holding a piece of banded sandstone from Colorado with micro-fault offsets in the layers.
It is clear to see how Jantzen followed a path from geologist and materials scientist to philanthropist. Ted Fredericks, a lover of geology and an avid rock collector, first placed a pick ax in his daughter's hand at the age of two while on one of the family's many mineral hunts. When he turned his passion for rock collecting into a business assembling educational rock kits for museums and schools, young Carol earned pennies and crystals by helping to gather the samples in the field and labeling the specimens in preparation for distribution. And into her adult life, Christmas presents from her father were, predictably, mineral or fossil specimens.

"To say that I was predestined to be a scientist would be an understatement," says Jantzen, recently retired as consulting scientist with Savannah River National Laboratory (SRNL), also located in Aiken.

"I have a lot of museumquality pieces in my collection, and I wanted to make sure that it went somewhere where it could be kept intact, have longevity, and be enjoyed by the community," Jantzen says about her decision to place the gallery at RPSEC. "I also felt that a local facility with a planetarium would be the best place for a mineral gallery."

RPSEC is home to the DuPont Planetarium and already offers a dozen or more programs on rocks and minerals. Fredericks Mineral Gallery is a perfect fit.

My father's collection is a combination of specimens he found over the years or selectively purchased," she says. "Many of them were obtained from quarries that are now closed or built over and are quite rare."

The minerals in the collection are also notable for their size and the

beauty of their crystal structures. Just the type of pieces that can excite young minds.

Jantzen has a passion for science, technology, engineering, and math (STEM) education, especially for inspiring girls to pursue careers in science. She sees the potential for the gallery to play an important role in advancing this mission.

Gary Senn, director of RPSEC, is also delighted with the educational prospects of the gallery and sees it as a complementary part of the center's DuPont Planetarium and the Bechtel Telescope Observatory. "The Fredericks collection is truly Smithsonian quality and deserves to be displayed that way," Senn says.

Although Jantzen initially began planning the gallery in 2014 , her recent retirement has now provided her the time to ramp up development of the gallery in her role as affiliate faculty member at the University of South Carolina Aiken (USCA) where the RPSEC is co-located.

Jantzen's entire career seems to have been preparing her for this "retirement" project. Her nearly four-decade career at SRNL is replete with scientific awards, patents, and published papers. But as one of the few women in science early in her career, there were obstacles to overcome. She learned that she needed to over-perform just to be accepted as an equal among her male peers. And she 
was determined to minimize this bias by mentoring virtually every new female scientist who followed her into SRNL. This effort, combined with her natural instincts to understand the big picture of her projects and her penchant for looking to nature itself to unlock solutions, won the respect of her colleagues.

She applied these same energies in her decades of work in professional organizations. Jantzen served in some of the top roles in the Materials Research Society (MRS), including symposium organizer of Scientific Basic for Nuclear Waste Management, chair of the 1986 MRS Fall Meeting, and director and later secretary on the Board of Directors (known at that time as the Council). She was also elected as the first female president of The American Ceramic Society and served 14 years on its Board.

And all the while, she and her father continued to amass rock and minerals of the highest quality that now decades later will become the Fredericks Mineral Gallery.

Not surprisingly, she has been very hands-on in every detail of the design and construction of the gallery displays. She studied the mineral exhibits at the Tellus Science Museum (near Atlanta) and the Smithsonian National Museum of Natural History (in Washington, DC) as models for display concepts and construction.

\section{Currently installed in the gallery} are four displays covering the characteristics of rocks and minerals and an interactive flip board that challenges students to test their newly learned knowledge.

"There's a lot that goes into properly displaying the samples, and Tellus staff has been extremely generous with their time in helping me do this correctly," she says. "Among other things, the cases need to be properly ventilated to dissipate the heat from halogen lights and control dust," she says. "The use of appropriate type style and size in signage and labeling of the plinths is critical for legibility."

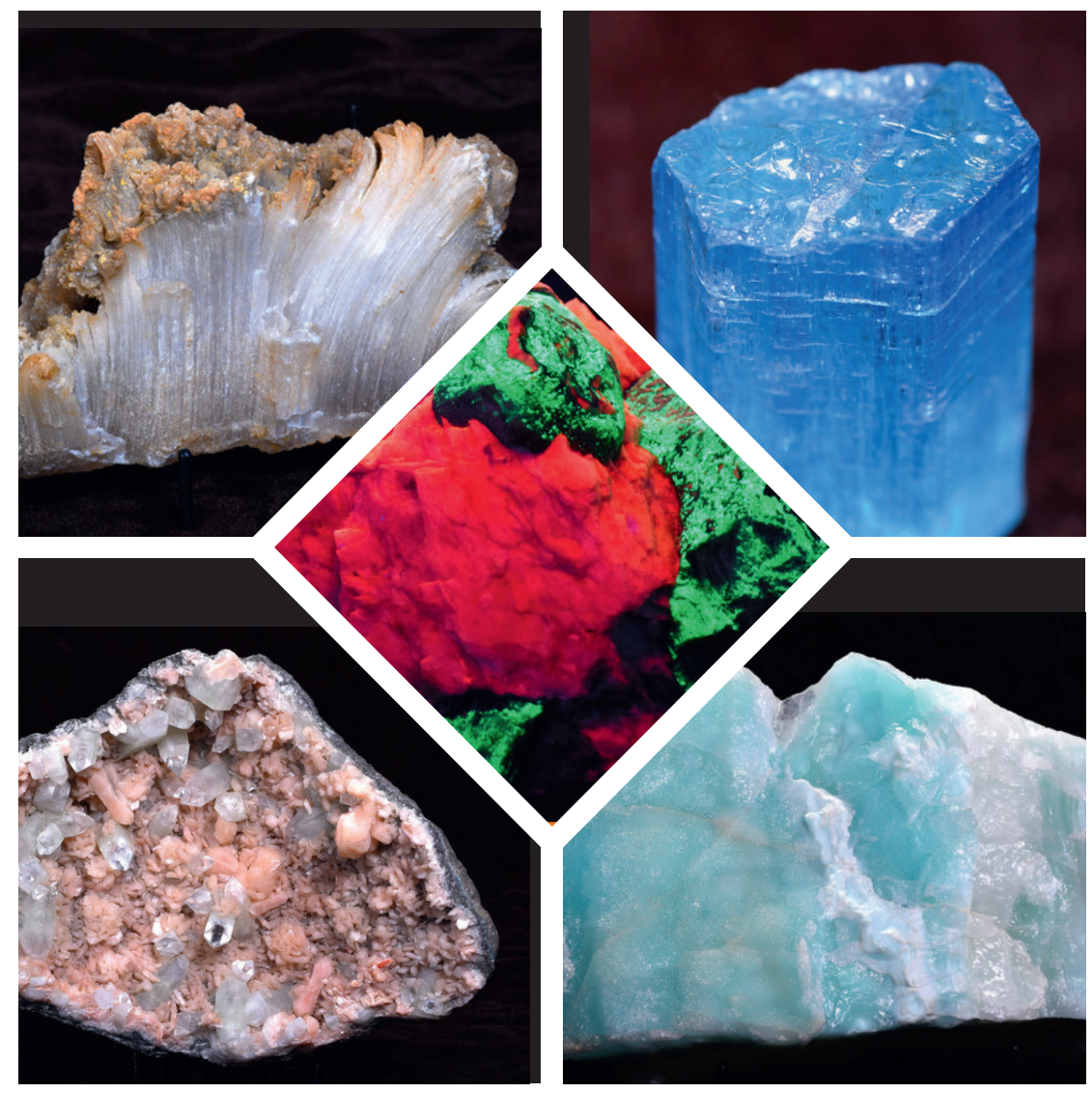

Top left: Gypsum $\left(\mathrm{CaSO}_{4}\right)$ cave flower from Mammoth Caves, Kentucky. Top right: Aquamarine or beryllium aluminosilicate $\left(\mathrm{Be}_{3} \mathrm{Al}_{2} \mathrm{Si}_{6} \mathrm{O}_{18}\right)$ from Afghanistan. This gem-quality specimen is 1.25 inches long. Bottom left: Apophyllite in stilbite. Apophyllite, $\mathrm{KCa}_{4} \mathrm{Si}_{8} \mathrm{O}_{20}(\mathrm{~F}, \mathrm{OH}) \cdot 8\left(\mathrm{H}_{2} \mathrm{O}\right)$, contains more hydroxide than fluorine compared to the other minerals in the apophyllite group. The apophyllite are the clear crystals. The pink is the stilbite, which is a hydrous calcium sodium and aluminum silicate, $\mathrm{NaCa}_{4}\left(\mathrm{Si}_{27} \mathrm{Al}_{9}\right) \mathrm{O}_{72} \cdot 28\left(\mathrm{H}_{2} \mathrm{O}\right)$. From Jalgaon-Maharashtra State, India. Bottom right: Vanadio cuprian aragonite from Laurium Mines, Sounion, near Athens, Greece. Center: Willemite crystals $-\mathrm{Zn}_{2} \mathrm{SiO}_{4}-$ (green) in calcite (red) from Franklin, N.J., under ultraviolet light. This calcite is enriched in a small amount of manganese, which helps it fluoresce.

Having RPSEC in the city that has been Jantzen's home for the past 37 years has also been an advantage. "It has been easier for me to facilitate getting the cabinets built and getting the artwork done in a place where I have a local network of carpenters, cabinetmakers, artists, and photographers that I've met along the way," she says.

Jantzen has a long list of exhibits she would like to develop. In the near-term, she is adding educational graphics to the Foucault's pendulum in the lobby, and she foresees the development of a rocktouching wall and displays of fluorescent minerals, specimens by geographic regions (South Carolina and international), fossils, rare zeolites, minerals you can eat, and many other ideas inspired by the Tellus and the Smithsonian. She also wants to provide a space for her collection of polished mineral eggs and be able to use her videos of volcanic eruptions. "I have lots of volcano videos," she says.

But before all of this can happen, each piece must be curated to establish its identity and provenance. Jantzen pursued a dozen or more potential appraisers before finding the one qualified for the task. The process of cataloguing the entire collection is also underway. This "paper trail" is needed to retain the integrity of the collection as the pieces are moved around during upcoming installation and upgrades and to secure the collection for future generations. 
Movement of the displays toward a permanent home in the center is likely to happen over the next year or two, propelling the process of cataloging to be completed now. At present the gallery is located in the lobby and classrooms. The DuPont Planetarium is scheduled to be moved elsewhere in the center, opening that space for Jantzen's collection.

Jantzen recognizes the enormity of the project but intends to work toward seeing it largely completed within the next 10 years. While she has contributed substantial funding from her parents' estate for display cases and educational artwork, she is now seeking additional funding that will support ongoing expansion of the gallery and maintain its intellectual vitality.

Even though her collection is worldclass, she is looking for new acquisitions. She is delighted to have already incorporated the Norm and Liz Baumann collection, which was added in 2014. The Baumanns, who also worked at SRNL (Liz was a chemist, Norm a nuclear engineer) were avid rock and mineral collectors.

"Their collection contains many minerals that complement the ones I have," says Jantzen, "including phantom calcite and rhodochrosite, which is manganese carbonate." And recently she has acquired a 39-inch-long dinosaur bone from Dinosaur, Col., as well as crystallized

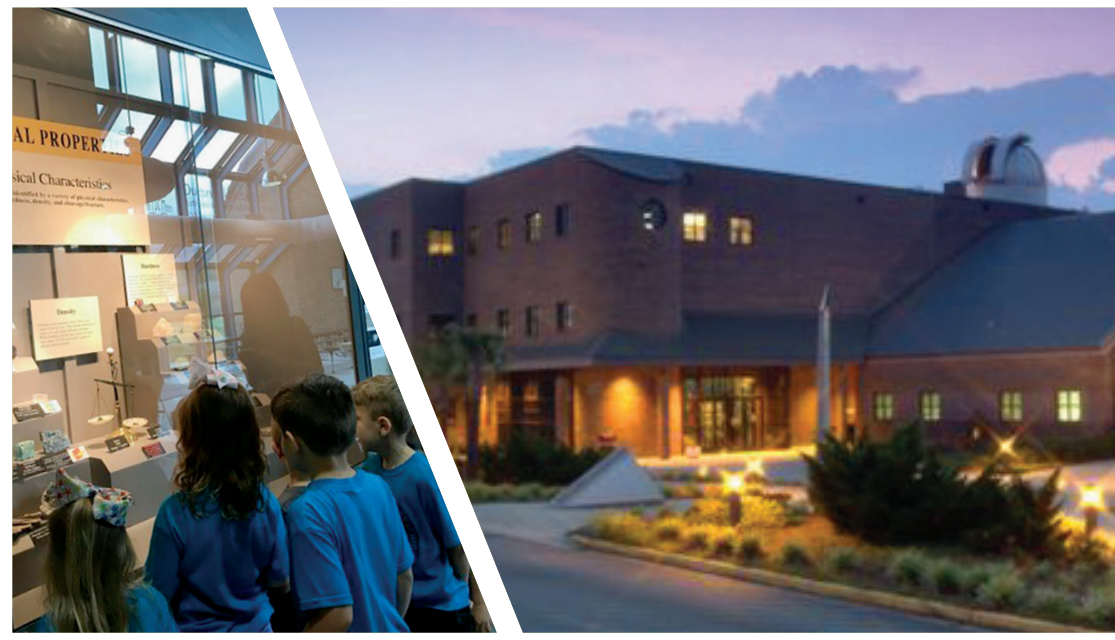

Young visitors learn about the characteristics of minerals at one of the displays in the Fredericks Mineral Gallery. The gallery, located in the Ruth Patrick Science Education Center, Aiken, S.C. (right), is helping to further the center's STEM education mission.

South Carolina minerals from two other SRNL scientists, Yates Donnan and Jesse Smith Donnan. She would particularly like to include more meteorites.

\section{"I am sure there are any number of scientists who have many fine mineral collections that they may want to share," Jantzen says.}

"The gallery is the place where they can be sure their collections will remain intact and will be acknowledged as their names will appear in the displays," Jantzen added.

With everything she is undertaking to develop the gallery, there is no real "retirement" for Carol Jantzen. But she has the rock-hard determination to achieve her crystal clear goal of generating a love of geology and earth science and enabling people to appreciate how natural minerals form in wondrous shapes and sizes.

For information on how to donate rock, mineral, and/or fossil specimens or make a monetary donation, contact Judith Goodwin at judithg@usca.edu.

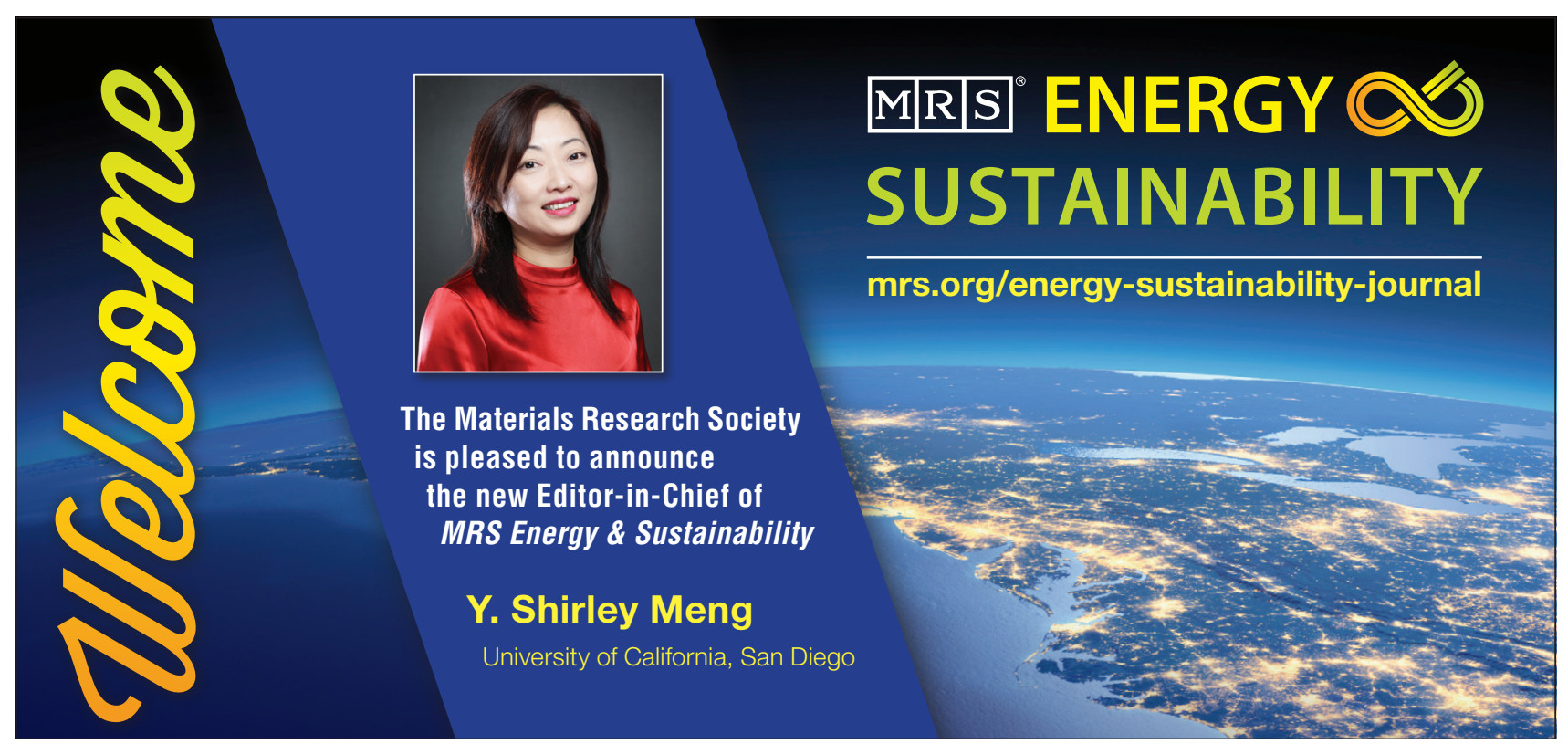

